\title{
Learning together
}

\author{
After a diagnosis of multiple sclerosis, Danny van Leeuwen describes his relationship with his \\ neurologist
}

\section{Danny van Leeuwen}

For more than 25 years I experienced episodes of weakness, shortness of breath, and dizziness. My primary care doctors ordered a full cardiac investigation each time I went to see him or her because my father had died from a heart attack when he was 45 . My tests were always negative. Then I developed trouble with my vision, and the weakness got worse and did not resolve. My balance was bad-I kept falling off my bicycle. I saw various specialists and had a magnetic resonance image scan. A diagnosis of multiple sclerosis was made. The neurologist I then saw said that I had had remitting relapsing multiple sclerosis for more than 20 years, and now I had secondary progressive multiple sclerosis. I thought that my life was over. I had worked as a nurse in physical rehabilitation and had seen multiple sclerosis at its worst. I was afraid I wouldn't be able to continue the work I loved, leading the patient and family experience initiative at Boston Children's Hospital.

\section{"Let's travel on this journey together"}

The neurologist surprised me. He said, "I'm an expert in medical treatment for populations with multiple sclerosis, but I don't know a thing about you. My job is to learn about you, and your job is to teach me about you. You are an experiment of one. Let's travel on this journey together."

I cried, I was so relieved. He started me on Solumedrol (methylprednisolone) infusions and asked me to draw up a list of personal goals. We had a family meeting. My goals were simple: I wanted the disease to progress as slowly as possible, to keep playing the saxophone, and to not take any drugs that would make me depressed (I've been told that I'm a pathological optimist and I know that's my greatest strength). At the next meeting my neurologist and I came up with a management plan: Copaxone (glatiramer); vitamin D; physiotherapy for mobility, safety, and strength; and to continue to play the saxophone. He said playing the saxophone is the best treatment for multiple sclerosis-it helps my lung capacity, dexterity, and mood.
I then started to get intense tingling in my lower arms and hands, electric zaps from my groin to my feet, and severe leg cramps. The neurologist wanted to put me on gabapentin. I asked if it would dull my mind. He said it might. I filled the prescription but couldn't bring myself to take it. I went to a massage therapist and acupuncturist. At the next visit to the neurologist I told him what I had done. He said, "I'm not an expert in those modalities, but I support anything that works for my patients. Keep the gabapentin. Take it if the pain gets intolerable. And keep me informed." I thought I had died and gone to heaven.

\section{Shared goals and shared understanding make all the difference}

It was tough for a while. I was scared and hypervigilant about any real or imagined symptom. The neurologist signed me up for the electronic patient portal so I could communicate with him easily. I probably sent 25-30 texts over three months with questions and concerns. He or his nurse responded with "don't worry about it" (most of the time), or "if you still experience that tomorrow let me know," or "I need to see you today" (this only happened once). Together we settled on a care plan of exercise, acupuncture, massage, meditation, and paracetamol as needed. The pain isn't gone, but I can tolerate it and function pretty well. I am not in a regular job but work when I can. I see the neurologist once or twice a year now and he always asks, "Have you fallen?" "Are you still playing the sax?" He says that these are my personal outcome measures. I like that I have a barometer, and that he knows me and cares.

Competing interests: I have read and understood BMJ policy on declaration of interests and declare the following: none.

Published by the BMJ Publishing Group Limited. For permission to use (where not already granted under a licence) please go to http://group.bmj.com/group/rights-licensing/ permissions 


\section{What you need to know}

- Get to know your patient, help her or him to figure out personal goals, and use these to develop a shared care plan

- Be appreciative of the patient's capabilities and knowledge of what works for her or him

- Patients value being able to communicate easily online with members of their clinical team and getting continuity of care from them

\section{Education into practice}

Many clinicians and patients hope for relationships as productive as this. What day to day barriers do you find to achieving such a relationship?

A frank delineation between the doctor being the disease expert and the patient being their body expert seemed to help here. How do you set expectations about your role in a patient's care? Are there ways in which you could alter this?

The doctor did not lose sight of the goals that mattered to the patient. How do you mentally or in your documentation keep track of the things that matter to people? Are there ways in which you can do this better?

A flexible approach to clinical contact worked here with a mixture of face to face visits and text service. In what ways can your patients contact you? Are there different ways you could do this? Which groups of patients might this help?

On the basis of reading this article do you reflect on your practice differently, or plan to change it? 